\title{
The financial toxicity of multiple sclerosis
}

\begin{tabular}{|c|c|}
\hline $\begin{array}{l}\text { Multiple sclerosis (MS) is a } \\
\text { neurologic autoimmune disease } \\
\text { that is generally diagnosed in } \\
\text { young adults. It is a lifelong } \\
\text { condition, as it is currently } \\
\text { incurable. The medical costs are } \\
\text { high, as patients have to cover } \\
\text { frequent hospital visits and } \\
\text { prescription medications, such } \\
\text { as emerging disease modifying } \\
\text { drugs. As a result, many patients } \\
\text { do not adhere to treatment } \\
\text { plans, which further reduces } \\
\text { their quality of life. There are also } \\
\text { non-medical costs to consider, } \\
\text { such as loss of productivity } \\
\text { at work and early retirement. } \\
\text { Research led by Professor Carl } \\
\text { Asche at the University of Illinois, } \\
\text { explores the financial burdens } \\
\text { and advocates for improved } \\
\text { strategies to reduce the cost } \\
\text { burden of the disease. }\end{array}$ & $\begin{array}{l}\text { ultiple sclerosis (MS) is an } \\
\text { autoimmune condition } \\
\text { that affects the brain and } \\
\text { spinal cord. Specifically, the immune } \\
\text { system attacks the myelin sheath, the } \\
\text { protective layer surrounding the nerves. } \\
\text { As a result, electrical transmission along } \\
\text { the nerves become disrupted, causing } \\
\text { a range of symptoms including blurred } \\
\text { vision, uncoordinated movement, } \\
\text { and muscle stiffness. As well as } \\
\text { physical symptoms, patients are also } \\
\text { at an increased risk of experiencing } \\
\text { depression. MS can affect people of } \\
\text { any age but most are diagnosed in } \\
\text { their 20s and } 30 \text { s, making it the most } \\
\text { common cause of disability in young } \\
\text { adults. It is estimated that one million } \\
\text { people in the United States and } 2.5 \\
\text { million people globally are living with } \\
\text { MS, with approximately } 12,000 \text { new } \\
\text { cases diagnosed each year in the } \\
\text { United States. }\end{array}$ \\
\hline
\end{tabular}

MS is a chronic, progressive, and incurable disease. Patients can only manage the symptoms throughout their lifetime. Due to long-term management of the dise costs. As MS progresses, an onsete of new symptoms will require more emergency care and hospitalisations for patients.

FINANCIAL COSTS

A systematic review of fifteen studies found that total direct and indirect costs per patient ranged from $\$ 8,529$ to

$\$ 54,244$ annually. Direct costs include

medical bills, such as hospitalisations

and pharmaceuticals, and comprise

$77 \%$ of the total cost, with prescription

medications accounting for majority

of the cost. Indirect costs include

expenses associated with short- and

long-term disability, productivity losses, comprise $23 \%$ of the total cost. In general greater the disease progression,

the cost associated with treatment and

social activities and productivity loss) will

increase exponentially.

MEDICAL COSTS OF MS

Using data from the National Inpatien Sample database in the United States from 1994 to 2013, it was projected

that MS hospital admissions will

exceed $\$ 43.5$ million by 2017, with

an estimated increase of $\$ 500,000$

annually. Before 2000, it was estimated

that the cost of hospitalisation

accounted for $30 \%$ of total costs

burdening patients. In 2013, it was

MS patients in the United States wa

MS patients in the United States was
approximately $\$ 755$ million and $\$ 198$

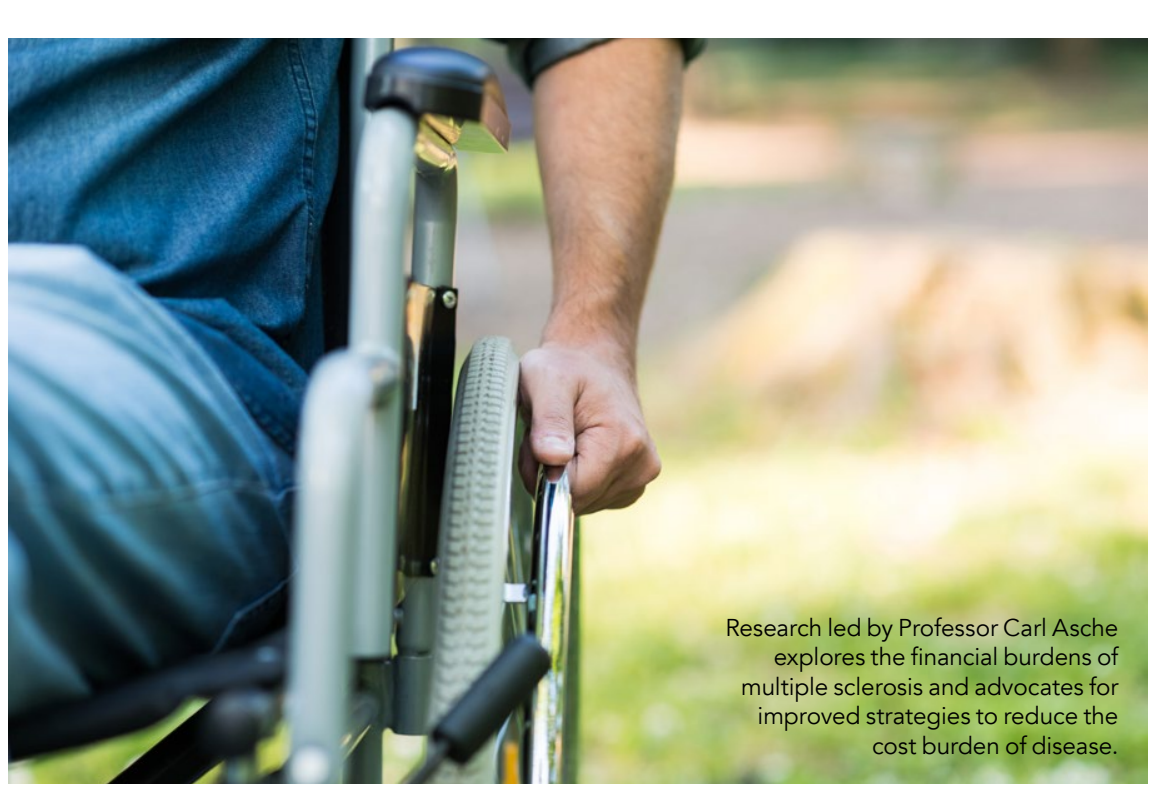

million, respectively, and was projected People living with MS may find that to increase at a rate of $\$ 40$ millon and their daily lives can be improved patients a ro require imaging scans like MRI during diagnosis and follow- The cost of home modifications vary up hospital visits to assess levels of widely and estimates range from lesions in the brain and spinal cord, $\quad \$ 100$ to $\$ 50,000$. Home modification

which can incur large medical bills. $\quad$ assistance programmes not only

in

study of 243 patients found that $34.7 \%$

(75 patients) reported non-adherence

to care (medications and imaging)

due to treatment expenses. $26.9 \%$ of

participants also reported delaying filling

of prescription medication because they were too expensive or were denied

of insurance coverage. Therefore, MS

patients are at a risk of low health-related

quality of life, as they are subjected to

high levels of anxiety to manage finances

and often do not adhere to treatment

further debilitates their well-being throug increased risks of relapse, subsequent

department visits.

Prescription drugs incur the largest cost

of MS management. A new type of

treatment for MS is the disease modifying

drugs (DMDs). On average, patients with

relapsing remitting MS experience one or

relapsing remitting MS experience one or

based on data of MS patients are at an increased risk of which can be very

$20 \%$ of admissions facing financial hardship that often results do distressing. DMDs aim results to reduce inflammation extrapolated, the in non-adherence to treatment plans. $\quad \begin{aligned} & \text { in the nerve cells for } \\ & \text { people with relapsing }\end{aligned}$ total national bil

for managing MS is estimated at $\$ 4.3$ benefit people with MS by allowing billion in 2013. This is a huge economic them to stay safe and independent burden for both patients and taxpayers. in their own homes but also result in

Even though insurance in the United States can cover part of the medical costs for MS patients, they would still need to pay for out-of-pocket costs, depending insurance coverage study tracked spending on out-of-pocket costs by found that out-of-pocket costs were seven times higher than a decade earlier. Among medically bankrupt individuals, MS is associated with the highest total out-of-pocket spending, at an average of $\$ 34,167$ at the point of bankruptcy filing

THE IMPORTANCE OF HOME MODIFICATIONS Home and work modifications are very important for individuals with MS. Home modifications to improve safety for MS patients fall under the umbrella of medical relapses. The popularity of this drug has
increased over the years but so has the costs in the last 20 years. Prices are set to for the continue increasing over the foreseeable admission to long-term care facilities. firt-genertion DMDs was shown to

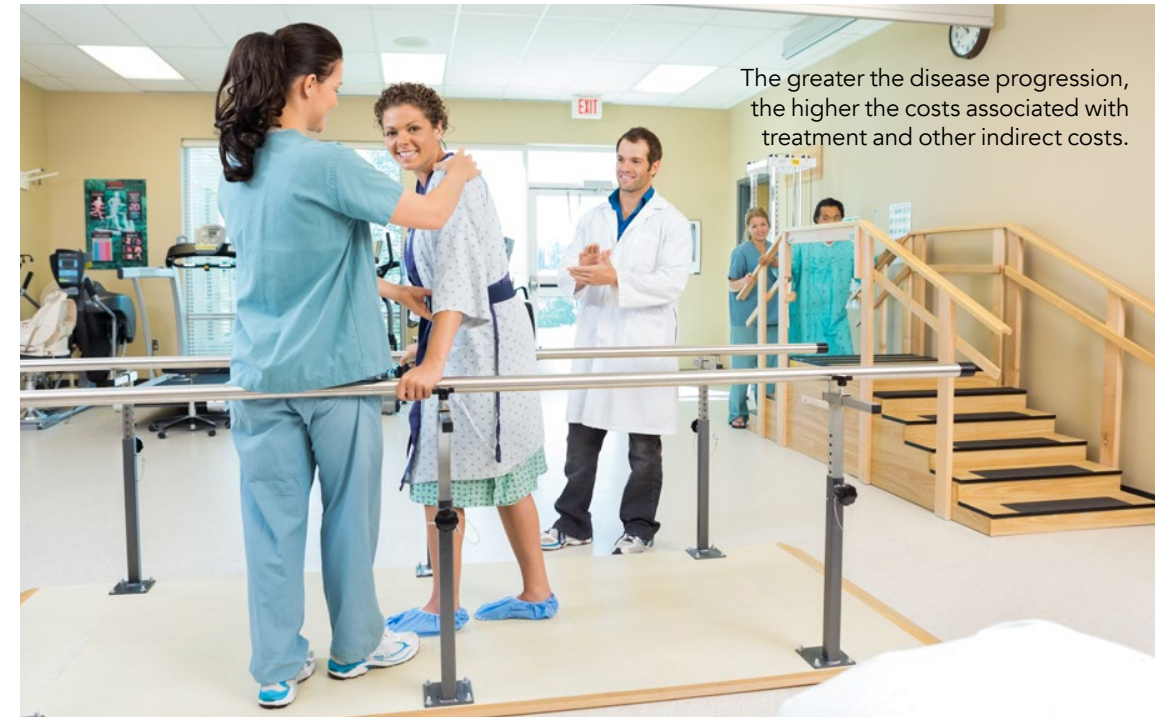




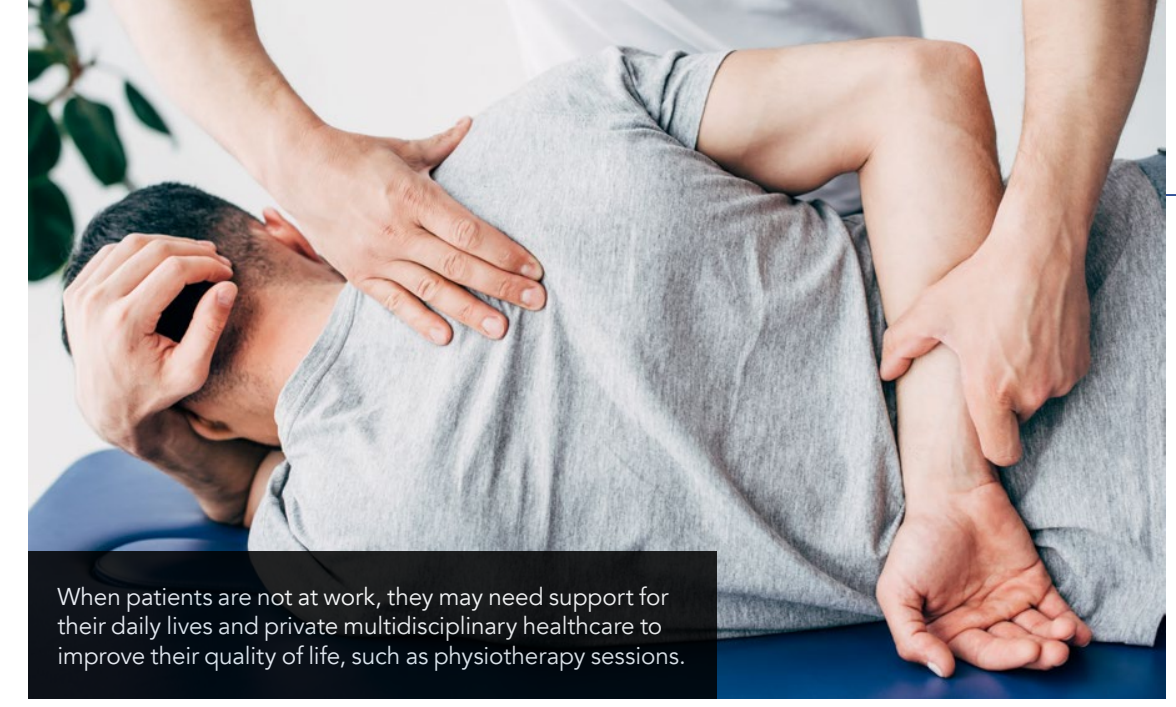

increase annually at a rate of five to seven times higher than that of prescription drug inflation. First-generation DMDs originally cost $\$ 8,000$ to $\$ 11,000$ when they entered the market, but now cost approximately $\$ 60,000$ annually. Newer generations of DMDs commonly costs

Some researchers have suggested that due to the effectiveness of DMDs, increased by 23.6\%. Thus, unemployment rates remain high within the community. For those who do retain a work schedul there are indirect costs to consider, such as productivity loss due to lost work hours patients lost an average of $€ 8,807$ due to work-related costs, such as absenteeism (loss of work efficiency done by a sick patient). When patients are not at work, hospital admission rates would decrease, they may need support for their daily lives medications. Non-profit organisations,
such as HealthWell

durable medical equipment such as . to allow for more indapendence and mobility as the disease progresses.

Implementation of workplace strategies for job retention amongst MS patients is essential to decrease further debilitating non-medical effects of the disease. Studies have also shown that effective therapies, such as high-efficacy DMDs at early stages of MS can significantly improve work productivity and lower the overall cost of economic burden.

MS is an expensive disease. Patients often worry about medical debt, expensive treatments, high rates of disability that However, there exist patient assistance companies from pharmaceutical to those who cannot afford the hospital admission rates would decrease, they may need support for their daily lives medications. Non-profit organisations,
such as HealthWell therefore saving health care costs.
Others have suggested that rising prices alienate most patients, resulting

First-generation disease modifying drugs such as HealthWel
Foundation, they entered the market, but now cost Network (PAN) increased number of approximately \$60,000 annually.

Patient Advocate Foundation offer excellent assistance relapses, and shorter
remission periods, which would then require more hospital visits. It is important to note that these drugs cost two to thre times higher in the United States tha other Western countries.

\section{NON-MEDICAL EXPENSES OF MS} Patients also face large non-medical expenses, regardless of disability levels. The social cost of MS is high because of the disease's long duration and has higher prevalence amongst younger adults. This hinders the ability to maintain studies and work over time. Younger patients are more prone to unemployment and significant productivity losses. According to the 2016 Global MS Employment Report, $43 \%$ of unemployed MS individuals quit work in the first three years after diagnosis, with $62 \%$ stating that tiredness was the main contributing factor

In Spain, a study of 199 patients with low MS disability found that employment rate Tell from $70.6 \%$ to $47.2 \%$ after diagnosis. The mean retirement age was 43.6
and the number of retiring patients and private multidisciplinary healthcare to improve their quality of life, such as physiotherapy sessions. The average cost of annual professional support (such as physiotherapy sessions and paid help for
housework) and informal caregiver services are estimated at $€ 1,027$ and $€ 1,329$, a walking aid a few years after disease onset further adding onto the living cost of MS. The financial burden is even high with the need for other more expensive

their living costs do not mount up and quality of life can be improved. Thorough and improved discussions surrounding costs has to occur between healthcare professionals and patients when planning freatment strategles. It will be interesting to Sa us Scale (EDSS) in furce work. Pollyes maging and medication are abo to so the economic burden shared by MS patients can be decreased. housework) and informal caregiver sevic stratify cost with The Expanded Disability and premature retirement. In the study, requires assistance, and lost income.

\section{Research Objectives}

The research of Professor Carl Asche focuses on the use of comparative effectiveness research and cost-effectiveness analysis in health care decision making.

\section{Detail}

Address

University of Illinois College of Medicine at Peoria

One Illini Drive, Peoria, Illinois 61605 USA

Bio

Carl V. Asche, MBA, MSc, PhD, is a Research Professor of Medicine and Neurology at the University of llinois Colleg of Medicine at Peoria. He is also a Research Professor of Pharmacy Systems, Outcomes \& Policy at the University of llinois College of Pharmacy at Chicago. He serves committees and his research is funded by a variety of state federal agencies.

Funding

-MS Council of Central Illinois

- OSF Foundatio

Collaborators

- Douglas R. Juvinall MD (OSF Illinois Neurological Institute, Peoria, llinois)

- Reuben Valenzuela, MD (HSHS Neuroscience Center,

Springfield, llinois)

- Jorge C. Kattah MD (Department of Neurology, University of Illinois College of Medicine, Peoria, Illinois: OSF Illinois Neurological Institute, Peoria, Illinois

- Tiffani S. Franada, DO (OSF Illinois Neurological Institute, Peoria, Illinois) - Leann Stickel

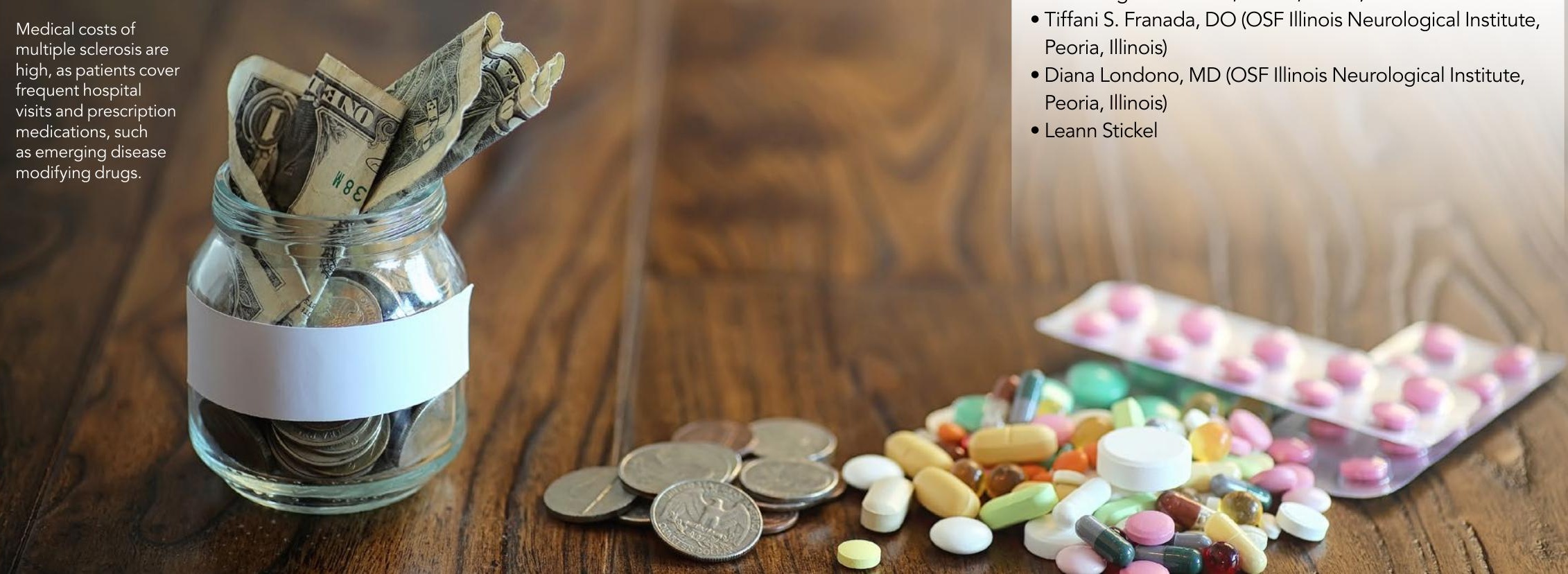

\section{References}

Adelman, G Rane, SG \& Villa, KF (2013). The cost burden of multiple sclerosis in the United States: A systematic review of the literature. Journal of Medical Economics, 16 (5), 639-647. Chen, AY Chonghasawat, AO \& Leadholm, KL (2017). Multiple sclerosis: Frequency, cost, and economic burden in the United

García-Domínguez, JM Maurino, J Martínez-Ginés, ML Olga, $C$ et al (2019). Economic burden of multiple sclerosis in a population with low physical disability. BMC Public Health, 19 Hartung, DM Bourdette, DN Ahmed, SM \& Whitham, RH (2015). The cost of multiple sclerosis drugs in the US and the pharmaceutical industry: Too big to fail? Neurology, 84 (21),

NHS. (2018). Multiple sclerosis. [Online] NHS. Available at: https:///www.nhs.uk/conditions/multiple-sclerosis/[Accessed

Multiple Sclerosis Trust. (2019). Disease modifying drugs (DMDs). [Online] Multiple Sclerosis Trust. Available at: https:// mstrust.org.uk/about-ms/ms-treatments/disease-modifying-

Sadigh, G Lava, N Switchenko, J Duszak, R et al (2020). Patient-reported financial toxicity in multiple sclerosis: Predictors and association wh car

\section{Personal Response}

How can medical and non-medical costs be decreased for patients?

II Removal of step therapy requirements from insurance companies mandating that patients try a lower efficacy
$D M D$ prior to starting a higher efficacy DMD, thus leading to increased disease activity and hospitalisations. Immediate response from the insurance company when a sugcted or a peer-to peer review can be inithed to get the patient on the appropriate medicine in a timely fashion. This a not covered under insurance, with a pop-up box forction is alternatives that are covered Reducing the cost of MRI scans for patients that require them yearly.

年 